\title{
Influence of swirl and tumble motion inside the combustion chamber of a compression ignited engine on vertices formation
}

\author{
Dan Moldovanu ${ }^{1, *}$, Florin Mariașiu ${ }^{1}$, Norbert Bagameri ${ }^{1}$ \\ ${ }^{1}$ Technical University of Cluj-Napoca, Cluj-Napoca, Romania
}

\begin{abstract}
In modern compression ignited engines, one of the key innovative directions is optimization of the burn process especially to reduce emissions. This optimization can be done by ensuring a better air-fuel mixture. To answer this problem, in the current paper, the authors analysed the vertices formation and velocity inside the combustion chamber in thirteen cases, by using numerical analysis (AVL FIRE Software), to generate pure tumble motion, pure swirl motion, no in-cylinder motion of the air, and other combinations on tumble and swirl motion. The cases that were chosen combine $0 \%, 50 \%, 70 \%$ and $100 \%$ tumble and swirl motion. The greatest velocity of the in-cylinder air motion was noted when a $100 \%$ tumble and $50 \%$ swirl motion was induced $(77.2 \mathrm{~m} / \mathrm{s}$ at 736 degrees CA), while the smallest velocity was noted at $100 \%$ swirl and $0 \%$ tumble $(71.07 \mathrm{~m} / \mathrm{s}$ at 736 degrees $\mathrm{CA})$. Because of the different induced motions, the vertices that form inside the combustion chamber have a great influence on air-fuel mixture and implicitly on emissions.
\end{abstract}

\section{Introduction}

Current European laws restrict harmful emissions through several amendments, especially for Diesel engines. Therefore, a large number of papers investigate all possible directions for this cause.

Payri et.al. chose the direction of measuring tangential and radial velocity components of a Light Duty Vehicle (LDV) with accent on the flow patterns inside the 4-valve single cylinder diesel engine for various engine speeds, underlining swirl numbers and piston-bowl geometries, under similar conditions to those of a production engine. Their work was focused on the near-wall region of the axisymmetric combustion chambers because of the emissions formation. And their conclusion was that the piston bowl shape and intake configuration affect the flow patterns and the turbulence level [1].

The main in-cylinder motion inside a spark ignited engine is the tumble motion which affects the air-fuel mixture and therefore the emissions. Kim et.al. used a commercial code (STAR-CD) to investigate the mixture formation and combustion characteristics in a sprayguided GDI engine. To predict the breakup of the spray, the Reitz-Diwakar's breakup model was used for the ultralean mixture operating mode. The results shown that enhanced tumble flow can deteriorate the mixture distribution of the hollow cone spray, and therefore decreases the burning rate [2].

Yadollahi et.al. investigated the effect of combustion chamber geometry on injection and mixture preparation in a $\mathrm{CNG}$ direct injection SI engine. By changing the combustion chamber geometry, the air-fuel mixture changes. The results show a strong sensitivity to grid size across the nozzle diameter and the cylinder head forces a non-symmetrical flow field inside cylinder [3].

Hill and Zhang have written a paper regarding the rotating flow (swirl and tumble) in premixed sparkignition engines and its effects on turbulence generation and flame propagation. Both motions, swirl and tumble, have had many research devoted to them, in recent years the increasing attention being paid to tumble. Because the two motions have different characteristics and they interact differently with the piston motion, is has been concluded that an optimum rotating flow field may create through combination of the two kinds of rotational motion. In their paper the authors have reviewed the principal features of the mean velocity and turbulence fields associated with these rotational motions, the mechanisms for decay, generation, transport and enhancement of in-cylinder turbulence [4].

Another paper regarding the two motions was the one written by Lee et.al, concerning the effects of tumble and swirl flows on flame propagation in a four-valve sparkignition engine. Through many experiments the authors underlined that there is a correlation between the stronger tumble during induction and turbulence levels at the time of ignition, this leading to a faster flame development. Furthermore, the tumble and swirl mixture was found to be more effective than pure tumble in effecting rapid and stable combustion under lean mixture conditions [5].

Khalighi investigated the intake-generated swirl and tumble motions in a 4-valve engine with various intake configurations. The results of this study indicated that during the induction process the in-cylinder flow field is comprised of several large scale vertical motions (stable and repeatable) on different planes within the engine cylinder. Although no significant in-cylinder tumbling

\footnotetext{
* Corresponding author: dan.moldovnau@auto.utcluj.ro
} 
motion was observed in the engine with both intake valves operating, a well-defined tumbling flow structure was observed with shrouded intake valve configurations. The author also measured and evaluated the velocity fields, tumble and swirl ratios under transient conditions [6].

There were also many papers that have investigated the swirl and tumble motions in regards to the burner systems. For example, Syred and Beér have researched the combustion in swirling flows in order to underline that there is sufficient information to indicate that stratified or staged fuel or air entry may be used to minimize noise, hydrocarbon, and most importantly NOx emissions from swirl combustors [7]. Furthermore, there were papers who further researched the burner systems in regards to energy, combustion and flame and heat transfer and NOx emissions [8-11].

\section{Methodology}

The methodology used for the current simulation starts with the correct input data. The simulation mesh and boundary were made using FIRE ESE DIESEL, where the general data were, the piston was created from a template piston shape, after measuring the real piston section. After introducing the geometry of the piston, the actual compression ratio was checked.

The next step was to generate the $3 \mathrm{D}$ meshes and check all the moving meshes for triangle faces. The final mesh is presented in Fig. 1.

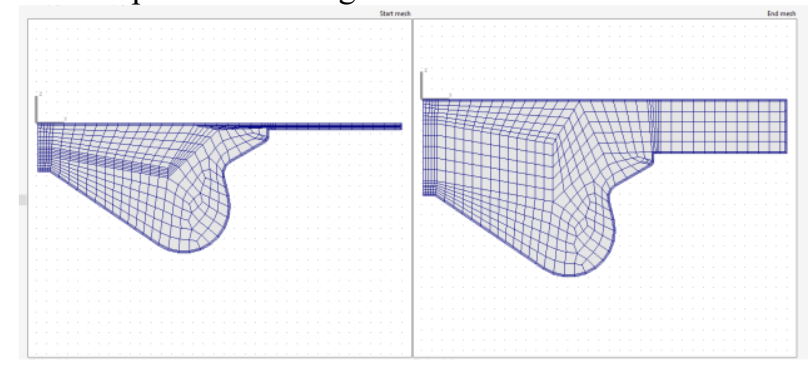

Fig. 1. Final mesh

The selections that were made are for:

$\checkmark$ the piston bowl - mesh movement and an imposed temperature of $575.15 \mathrm{~K}$,

$\checkmark \quad$ cylinder liner - wall boundary condition, with a temperature of $475.15 \mathrm{~K}$

$\checkmark \quad$ cylinder head - wall boundary condition with a temperature of $550.15 \mathrm{~K}$

$\checkmark$ the symmetry selection - symmetry boundary chosen.

After having the moving mesh, the Solver Steering File was completed, starting with Crank-angle run mode (from 540 to 800 deg CA), with module activation for species transport, spray (the module that simulates sprays based on the Discrete Droplet Method (DDM), which represents a spray as a statistical sample of discrete parcels.) and emissions.
The main idea of the paper was to change the movement of the air inside of the cylinder before the start of injection so that the fuel is injected in different types of vertrices and different air-fuel mixtures form.

For the simulations, a pure swirl motion simulation was made and a pure tumble simulation was made, after that, the cases that were chosen combine $0 \%, 50 \%, 70 \%$ and $100 \%$ tumble and swirl motion.

Table 1. Simulated cases (T-Tumble, S-Swirl motions).

\begin{tabular}{|l|l|l|l|l|l|l|}
\hline $\begin{array}{l}\text { Case } \\
\text { no. }\end{array}$ & $\mathbf{1}$ & $\mathbf{2}$ & $\mathbf{3}$ & $\mathbf{4}$ & $\mathbf{5}$ & $\mathbf{6}$ \\
\hline $\begin{array}{l}\text { Sectio } \\
\mathrm{n}\end{array}$ & $50 \%$ & $70 \% \mathrm{~T}$ & $50 \% \mathrm{~T}$ & $50 \% \mathrm{~T}$ & $70 \% \mathrm{~T}$ & $70 \% \mathrm{~T}$ \\
& $\begin{array}{l}\mathrm{T} \\
50 \%\end{array}$ & $70 \% \mathrm{~S}$ & $70 \% \mathrm{~S}$ & $\begin{array}{l}100 \% \\
\mathrm{~S}\end{array}$ & $50 \% \mathrm{~S}$ & $\begin{array}{l}100 \% \\
\mathrm{~S}\end{array}$ \\
\hline
\end{tabular}

\begin{tabular}{|l|l|l|l|l|l|l|}
\hline $\mathbf{7}$ & $\mathbf{8}$ & $\mathbf{9}$ & $\mathbf{1 0}$ & $\mathbf{1 1}$ & $\mathbf{1 2}$ & $\mathbf{1 3}$ \\
\hline $0 \% \mathrm{~T}$ & $0 \% \mathrm{~T}$ & $0 \% \mathrm{~T}$ & $100 \%$ & $100 \%$ & $100 \%$ & $100 \%$ \\
$0 \% \mathrm{~S}$ & $50 \%$ & $100 \%$ & $\mathrm{~T}$ & $\mathrm{~T}$ & $\mathrm{~T}$ & $\mathrm{~T}$ \\
& $\mathrm{~S}$ & $\mathrm{~S}$ & $0 \% \mathrm{~S}$ & $50 \% \mathrm{~S}$ & $70 \% \mathrm{~S}$ & $\begin{array}{l}100 \% \\
\mathrm{~S}\end{array}$ \\
\hline
\end{tabular}

\section{Results}

To show the influences of the imposed motions, sections were made, monitoring the velocity and direction of the air at 716 deg CA (2 degrees before the start of injection) and at $736 \mathrm{deg}$ CA ( 2 degrees after the end of the injection).

Since there are a lot of simulated cases, the results with the vertrices were presented for the most significant cases (Fig. $2-7$ ).

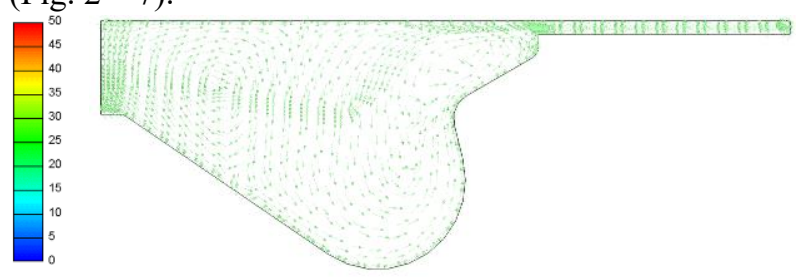

Fig. 2. Vertrices formation at $718 \mathrm{deg} \mathrm{CA}$, case 10

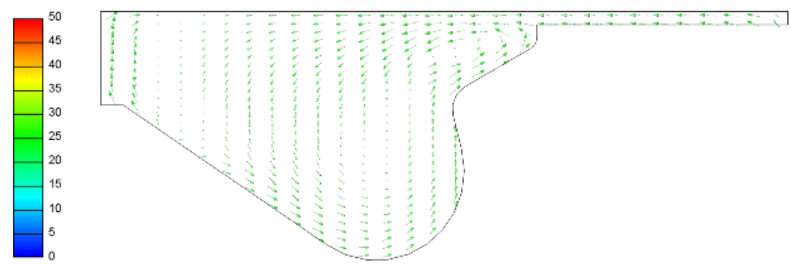

Fig. 3. Vertrices formation at $718 \mathrm{deg} \mathrm{CA}$, case 11

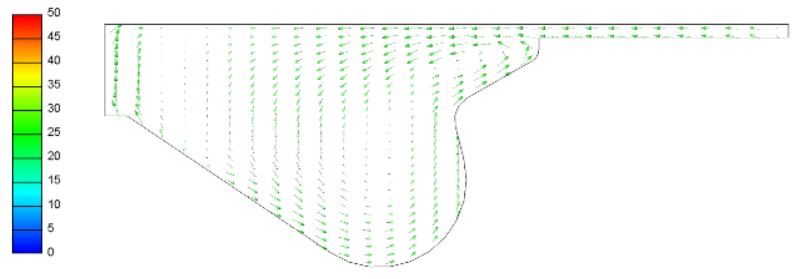

Fig. 4. Vertrices formation at $718 \mathrm{deg} \mathrm{CA}$, case 5 


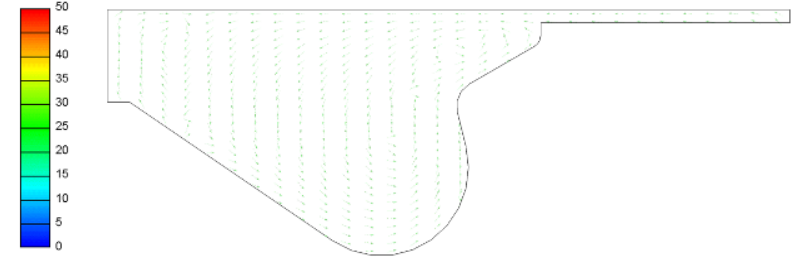

Fig. 5. Vertrices formation at $718 \mathrm{deg}$ CA, case 7

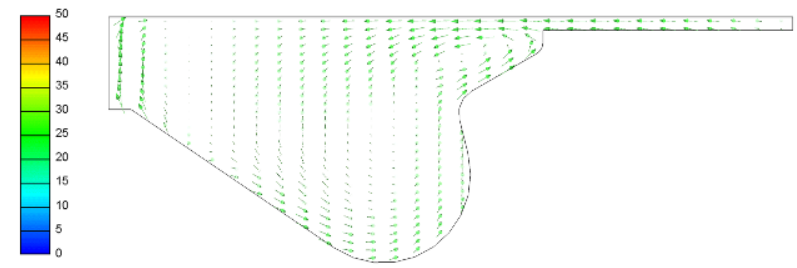

Fig. 6. Vertrices formation at $718 \mathrm{deg}$ CA, case 2

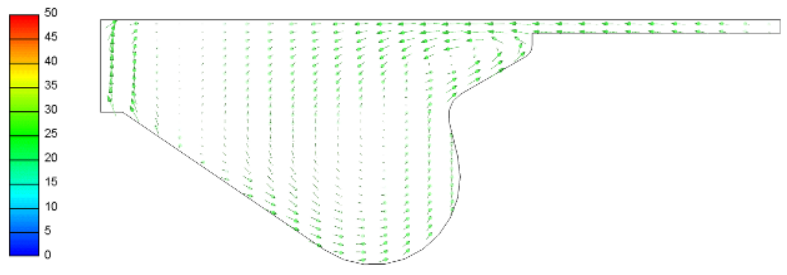

Fig. 7. Vertrices formation at $718 \mathrm{deg}$ CA, case 13

For the same cases, sections were also presented at 736 deg CA (Fig. 8 - 12).

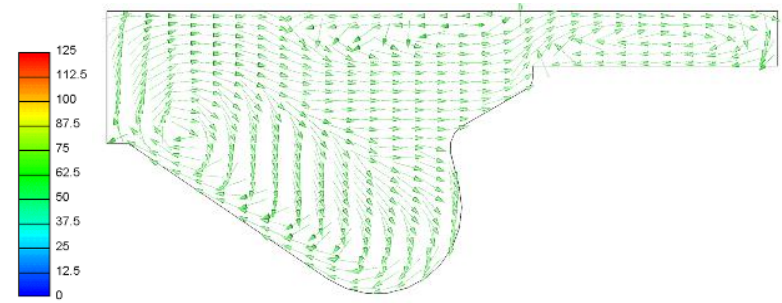

Fig. 8. Vertrices formation at $718 \mathrm{deg}$ CA, case 10

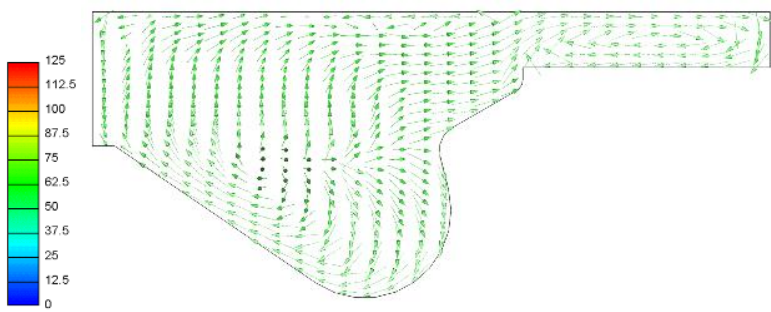

Fig. 9. Vertrices formation at $718 \mathrm{deg}$ CA, case 5

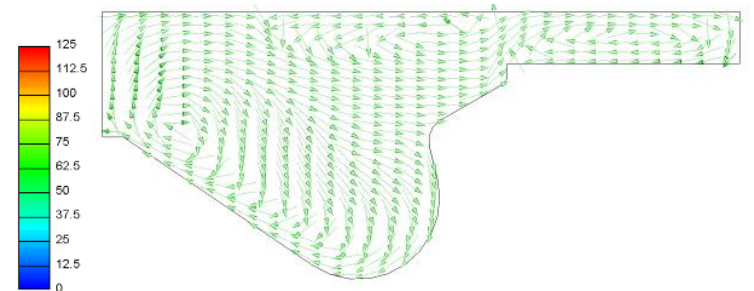

Fig. 10. Vertrices formation at $718 \mathrm{deg}$ CA, case 7

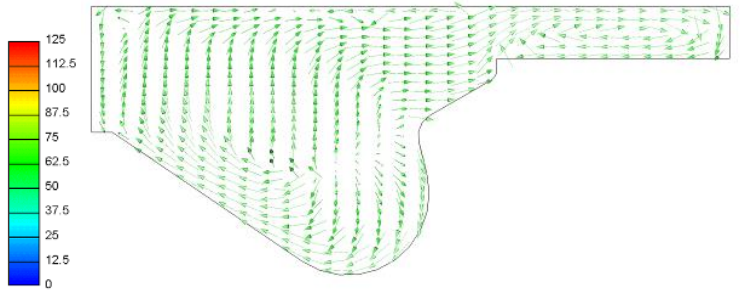

Fig. 11. Vertrices formation at $718 \mathrm{deg}$ CA, case 2

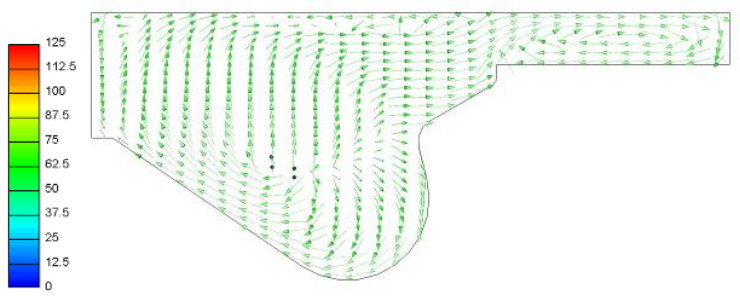

Fig. 12. Vertrices formation at $718 \mathrm{deg}$ CA, case 13

After observing the location and orientation of the vertrices, the maximum velocities were extracted for all sections and inserted in Table 2.

Table 2. Velocity results for all simulated cases

\begin{tabular}{|l|c|c|c|c|c|c|}
\hline Case no. & $\mathbf{1}$ & $\mathbf{2}$ & $\mathbf{3}$ & $\mathbf{4}$ & $\mathbf{5}$ & $\mathbf{6}$ \\
\hline $\begin{array}{l}\text { Velocity at } \\
718 \text { deg CA [m/s] }\end{array}$ & $\begin{array}{c}17,7 \\
7\end{array}$ & 17,7 & 18,7 & $\begin{array}{c}19,5 \\
2\end{array}$ & $\begin{array}{c}17,1 \\
7\end{array}$ & $\begin{array}{c}18,8 \\
7\end{array}$ \\
\hline $\begin{array}{l}\text { Velocity at } \\
736 \\
\text { deg CA [m/s] }\end{array}$ & $\begin{array}{c}74,5 \\
1\end{array}$ & 73,7 & $\begin{array}{c}72,6 \\
3\end{array}$ & $\begin{array}{c}72,2 \\
9\end{array}$ & $\begin{array}{c}75,9 \\
1\end{array}$ & $\begin{array}{c}73,2 \\
1\end{array}$ \\
\hline
\end{tabular}

\begin{tabular}{|l|c|c|c|c|c|c|}
\hline $\mathbf{7}$ & $\mathbf{8}$ & $\mathbf{9}$ & $\mathbf{1 0}$ & $\mathbf{1 1}$ & $\mathbf{1 2}$ & $\mathbf{1 3}$ \\
\hline $\begin{array}{l}\text { Velocity at } \\
\begin{array}{l}18 \text { deg CA [m/s] } \\
\text { deg }\end{array}\end{array}$ & $\begin{array}{c}16,2 \\
20,4 \\
2\end{array}$ & $\begin{array}{c}20,4 \\
1\end{array}$ & 15,9 & $\begin{array}{c}16,6 \\
5\end{array}$ & $\begin{array}{c}17,1 \\
2\end{array}$ \\
\hline $\begin{array}{l}\text { Velocity at } \\
736\end{array}$ & $\begin{array}{c}76,4 \\
\text { deg CA [m/s] }\end{array}$ & $\begin{array}{c}71,9 \\
6\end{array}$ & $\begin{array}{c}71,0 \\
7\end{array}$ & $\begin{array}{c}75,6 \\
5\end{array}$ & 77,2 & $\begin{array}{c}75,3 \\
3\end{array}$ \\
\hline
\end{tabular}

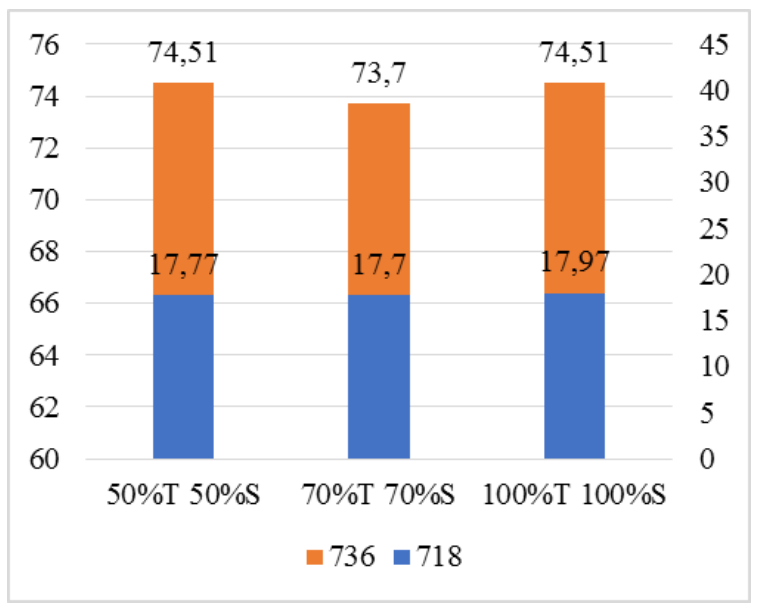

Fig. 13. Velocity $[\mathrm{m} / \mathrm{s}]$ at 718 and $736 \mathrm{deg} \mathrm{CA}$, cases 1,2 , 13. 


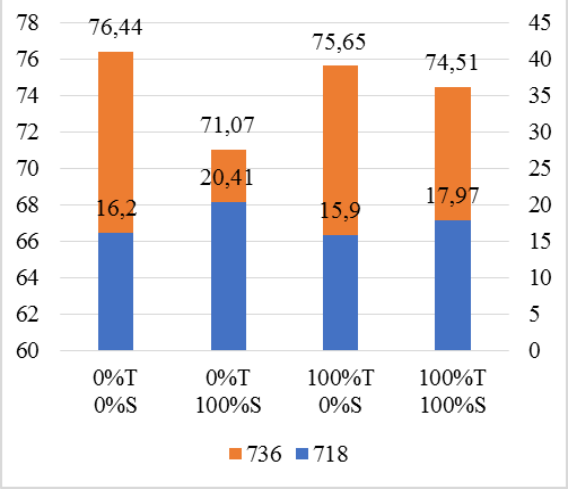

Fig. 14. Velocity $[\mathrm{m} / \mathrm{s}]$ at 718 and $736 \mathrm{deg}$ CA, cases 7, 9, 10,13 .

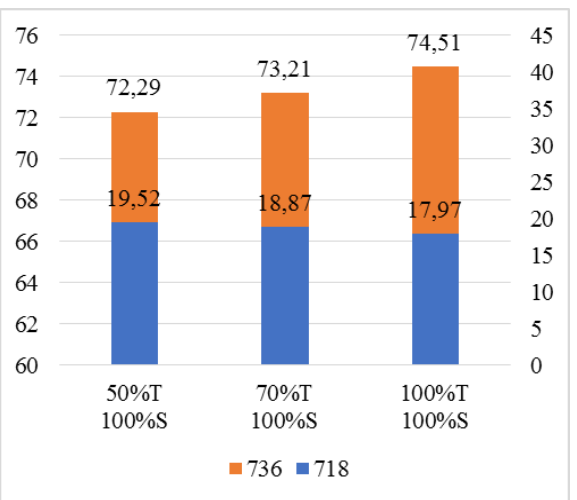

Fig. 15. Velocity $[\mathrm{m} / \mathrm{s}]$ at 718 and $736 \mathrm{deg} \mathrm{CA}$, cases 4, 6, 13.

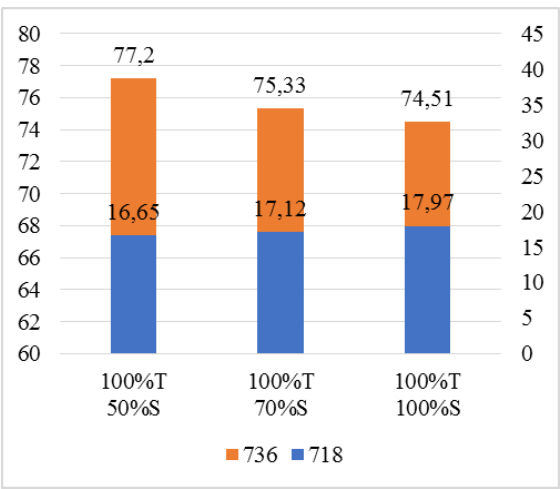

Fig. 16. Velocity $[\mathrm{m} / \mathrm{s}]$ at 718 and $736 \mathrm{deg} \mathrm{CA}$, cases 11 , 12,13 .

\section{Conclusions}

Taking into account all the gathered data, the conclusion is that the intake process is very important due to the air vertrices formation inside the combustion chamber.

Results have shown multiple vertrices like in Fig. 8, but also vertrices formed only because of the injection of the fuel.
An interesting fact is underlined by Fig. 15 and 16: as the tumble coefficient rises, the maximum velocity inside the cylinder rises, but if the swirl increases, the velocity inside the cylinder drops by $3 \mathrm{~m} / \mathrm{s}$, even though the initial motion had similar velocities.

\section{References}

1. F., Payri, J. Desantes, J. Pastor, Experiments in Fluids 22 (1996):. https://doi.org/10.1007/s003480050029

2. S., Kim, Y., Kim, J., Lee, "Analysis of the InCylinder Flow, Mixture Formation and Combustion Processes in a Spray-Guided GDI Engine," SAE Technical Paper 2008-01-0142, (2008), https://doi.org/10.4271/2008-01-0142.

3. B., Yadollahi, and M. Boroomand. "The effect of combustion chamber geometry on injection and mixture preparation in a $\mathrm{CNG}$ direct injection SI engine." Fuel 107 52-62 (2013).

4. P. G., Hill, and D. Zhang. "The effects of swirl and tumble on combustion in spark-ignition engines." Progress in energy and combustion science 20.5 373429 (1994).

5. K., Lee, B., Choongsik and K., Kernyong, "The effects of tumble and swirl flows on flame propagation in a four-valve SI engine." Applied thermal engineering 27.11-12 2122-2130 (2007).

6. B., Khalighi, "Intake-generated swirl and tumble motions in a 4-valve engine with various intake configurations-flow visualization and particle tracking velocimetry." SAE transactions 354-374 (1990).

7. N., Syred, J.M., Beer. "Combustion in swirling flows: a review." Combustion and flame 23.2 143-201 (1974).

8. J. C., Broda, et al. "An experimental study of combustion dynamics of a premixed swirl injector." Symposium (International) on Combustion. Vol. 27. No. 2. Elsevier, (1998).

9. P., Schmitt, et al. "Large-eddy simulation and experimental study of heat transfer, nitric oxide emissions and combustion instability in a swirled turbulent high-pressure burner." Journal of Fluid Mechanics 570 17-46 (2007).

10. N., Syred, "A review of oscillation mechanisms and the role of the precessing vortex core (PVC) in swirl combustion systems." Progress in Energy and Combustion Science 32.2 93-161 (2006).

11. L., Selle, et al. "Compressible large eddy simulation of turbulent combustion in complex geometry on unstructured meshes." Combustion and Flame 137.4 489-505 (2004). 